\title{
2015 IN HINDSIGHT
}

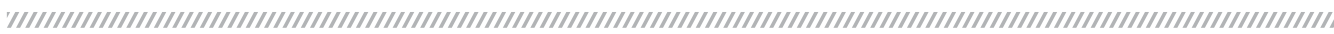

Dear Readers,

Heading into 2015, the global automotive industry was positioned somewhere in between - some markets were enjoying relatively strong growth and profitability, while many promising markets were heading into uncertainty. North America and Europe were looking up, while Russia and several Latin American markets experienced slump in sales. Growth in China had also somewhat slowed down, and experts were cautiously optimistic about the Indian market.

As we move to 2016, the overall situation hasn't changed much in the country, although sales have looked up since the festive season. One of the most important measures critical to sustained growth of the industry in the future - the Goods and Services Tax (GST) bill - still hangs in limbo, thanks to successive sessions being washed out in the Indian Parliament. As Arvind Balaji, President, ACMA has said in an interview to us, GST will help evolve a spoke and hub type of distribution system in the country, which is necessary for growth.

But the biggest newsmaker for the global automotive market in 2015 was diesel. First, it was the Volkswagen debacle, which put diesel technology under the scanner globally. Then the blame for the deteriorating air quality in New Delhi was squarely put on vehicles that run on diesel engines. So much so that the Supreme Court decided to order a partial ban on all diesel vehicles over 2,000 cc in the National Capital Region till March 31, 2016.

Singling out diesel for the mess in Delhi's air quality defies logic, for there are various other agents of emissions and pollutants that are equally responsible. Moreover, one fails to understand how banning new diesel vehicles, with cleaner emission technologies, would help in cleaning the capital's air. This has had unforeseen ramifications on a few manufacturers, and we hope the authorities and courts look at the problem of urban air quality with prospicience. Moving to higher emission standards is of course the best thing to do, but the route isn’t easy and will take time.

The current situation could well prove to be a shot in the arm for advocates of electric, hybrid and alternative fuel-based mobility. How industry leaders react strategically to these changes would define the long-term direction for the industry.

Wish you all a very happy and successful 2016!
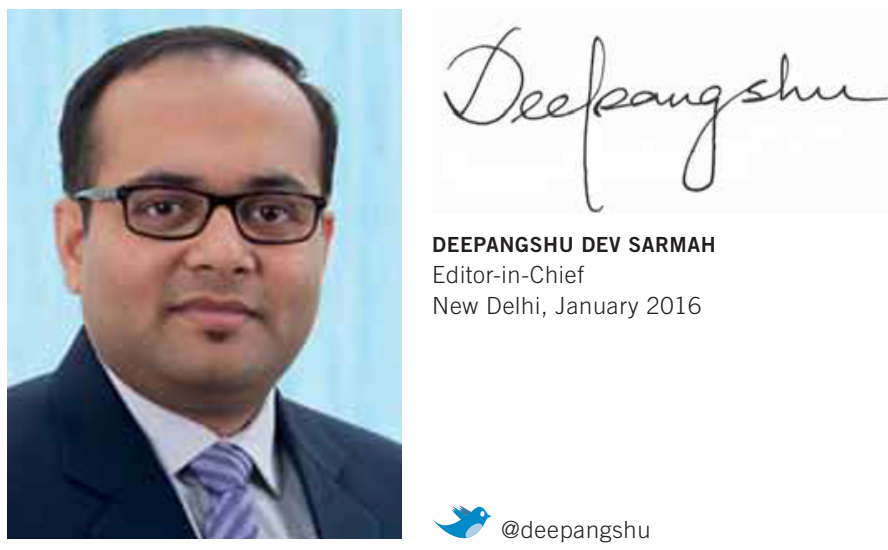

DEEPANGSHU DEV SARMAH

Editor-in-Chief

New Delhi, January 2016 